07;08;13

\title{
Плазменное отражение в мультизеренном слое узкозонных полупроводников
}

\author{
() Н.Д. Жуков, М.И. Шишкин ", А.Г. Роках
}

Саратовский национальный исследовательский государственный университет им. Н.Г. Чернышевского, Саратов, Россия

『 E-mail: shishkin1mikhail@gmail.com

Поступило в Редакцию 23 августа 2017 г.

В слоях электроосажденных субмикронных частиц и на шлифованных алмазным порошком M1 пластинах InSb, InAs, GaAs получены качественно одинаковые спектральные характеристики плазменно-резонансного отражения в области 15-25 $\mu \mathrm{m}$. Для самого узкозонного полупроводника InSb (граница собственного поглощения $\sim 7 \mu \mathrm{m})$ наблюдается спектральная полоса поглощения $2.1-2.3 \mu \mathrm{m}$, которая интерпретирована в модели оптического возбуждения кулоновски взаимодействующих электронов. В мультизеренном слое полученных химически наночастиц $\mathrm{PbS}(50-70 \mathrm{~nm})$ наблюдались максимумы поглощения 7, 10,17 $\mu \mathrm{m}$, которые можно объяснить электронными переходами по правилам квантования энергии для квантовых точек.

DOI: 10.21883/PJTF.2018.08.45973.17010

C развитием технологий полупроводниковых наноразмерных и субмикронных частиц начались активные исследования по созданию на их основе приборных, например, мультизеренных структур. При этом большинство работ посвящено широкозонным полупроводникам $\mathrm{A}_{2} \mathrm{~B}_{6}$ и исследованиям типичных для них явлений фотопроводимости, фото- и катодолюминесценции. Представляют, однако, научный и практический интерес исследования узкозонных полупроводников, спецификой которых является наличие в них суперлегких и суперподвижных электронов, что приводит, в частности, к проявлению квантово-размерных эффектов в наночастицах антимонида и арсенида индия относительно больших размеров $[1,2]$, плазменного резонанса в длинноволновой области и экзоэлектронной фотоэмиссии наночастиц узкозонной субфазы $\mathrm{Pb}_{x} \mathrm{Cd}_{1-x} \mathrm{~S}$ [3]. Изучение этих явлений в частицах и на их границах в мультизеренной структуре может позволить решать 
Сводка данных

\begin{tabular}{c|c|c|c|c|c|c|c|c|c|c}
\hline $\begin{array}{c}\text { Полу- } \\
\text { провод- } \\
\text { ник }\end{array}$ & $\begin{array}{c}n, \\
\mathrm{~cm}^{-3}\end{array}$ & $\begin{array}{c}E_{g}, \\
\mathrm{eV}\end{array}$ & $\varepsilon / \varepsilon_{0}$ & $m / m_{0}$ & $\begin{array}{c}\lambda_{r}, \\
\mu \mathrm{m}\end{array}$ & $\begin{array}{c}\text { рас- } \\
\text { чет }\end{array}$ & $\begin{array}{c}\text { экспе- } \\
\text { римент }\end{array}$ & $\begin{array}{c}\Lambda, \\
\mathrm{nm}\end{array}$ & $\begin{array}{c}n_{c}, \\
\mathrm{~cm}^{-3}\end{array}$ & $\begin{array}{c}\lambda_{p}^{*}, \\
\mu \mathrm{m}\end{array}$ \\
\hline $\mathrm{InSb}$ & $5 \cdot 10^{17}$ & 0.18 & 17 & 0.012 & 6.9 & 23 & 22 & $\sim 36$ & $\sim 2 \cdot 10^{16}$ & $\sim 110$ \\
$\mathrm{InAs}$ & $2 \cdot 10^{18}$ & 0.36 & 15 & 0.025 & 3.5 & 17 & 16 & $\sim 25$ & $\sim 7 \cdot 10^{16}$ & $\sim 90$ \\
$\mathrm{PbS}$ & & 0.38 & 17 & 0.055 & 3.1 & & & $\sim 22$ & $\sim 1 \cdot 10^{17}$ & $\sim 100$ \\
$\mathrm{GaAs}$ & $2 \cdot 10^{18}$ & 1.43 & 13 & 0.055 & 0.9 & 21 & 22 & $\sim 17$ & $\sim 2 \cdot 10^{17}$ & $\sim 60$ \\
$\mathrm{Si}$ & $\sim 5 \cdot 10^{19}$ & 1.12 & 11 & 0.5 & 1.1 & $\sim 10$ & 10 & $\sim 5$ & $\sim 8 \cdot 10^{18}$ & $\sim 25$
\end{tabular}

Пр имечани е. $n-$ концентрация электронов в зоне проводимости (по данным сертификата на материал), $\varepsilon / \varepsilon_{0}-$ относительная диэлектрическая проницаемость, $E_{g}-$ ширина запрещенной зоны, $\lambda_{r}[\mu \mathrm{m}]=1.24 / E_{g}[\mathrm{eV}]-$ „красная“ граница спектра собственного поглощения, $m / m_{0}$ - отношение эффективной массы электрона в зоне проводимости к его массе „покоя“, $\lambda_{p}$ - длина волны плазменного резонанса, $\Lambda=h(2 m E)^{-1 / 2}$ длина волны де Бройля для электрона $(h-$ постоянная Планка, $E-$ энергия электрона, отсчитанная от уровня Ферми), $n_{c}=\Lambda^{-3}-$ критическое (для кулоновского взаимодействия) значение концентрации электронов, $\lambda_{p}^{*}-$ расчетные крайние значения длины волны плазменного резонанса.

задачи регистрации и получения излучений в дальней инфракрасной и терагерцевой областях спектра.

Целью настоящей работы является исследование плазменного отражения и поглощения в широком спектральном диапазоне (от 1 до $25 \mu \mathrm{m})$ на мультизеренном слое узкозонных полупроводников электронной проводимости InSb, InAs и $\mathrm{PbS}$. Для сопоставления свойств проведены измерения на слоях относительно широкозонных арсенида галлия и кремния и монозеренной поверхности подложек InSb, InAs и GaAs. Использованные сведения из литературных источников [4-7], сертификатов и полученные в работе данные о свойствах и параметрах материалов и структур приведены в таблице.

Мультизеренная структура представляла собой электроосажденный на стеклянную подложку с ITO слой толщиной 5-10 $\mu$ m предварительно седиментированных частиц $\mathrm{InSb}$, InAs, GaAs, Si округлой формы $(1-3 \mu \mathrm{m})$, изготовленных путем мелкодисперсного дробления пластин на шаровой мельнице Pulverisette-7, и близких к кубической форме наночастиц $\mathrm{PbS}(40-70 \mathrm{~nm})$, полученных в результате химической реакции гидроксида натрия и нитрата свинца в водном растворе. Конт-

Письма в ЖТФ, 2018, том 44, вып. 8 


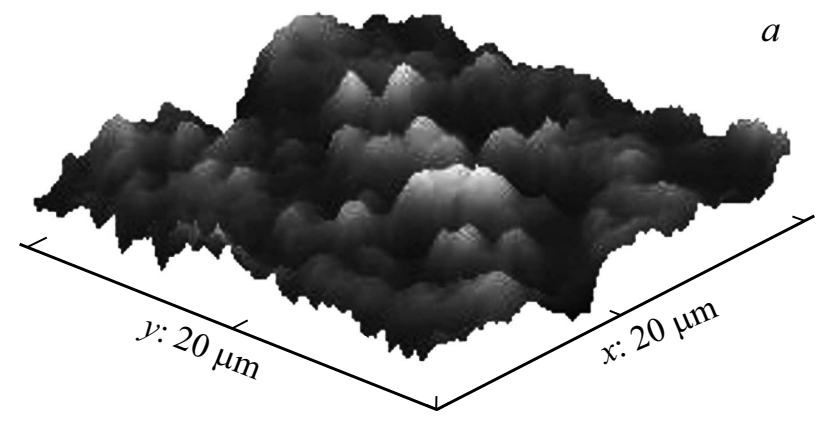

$b$

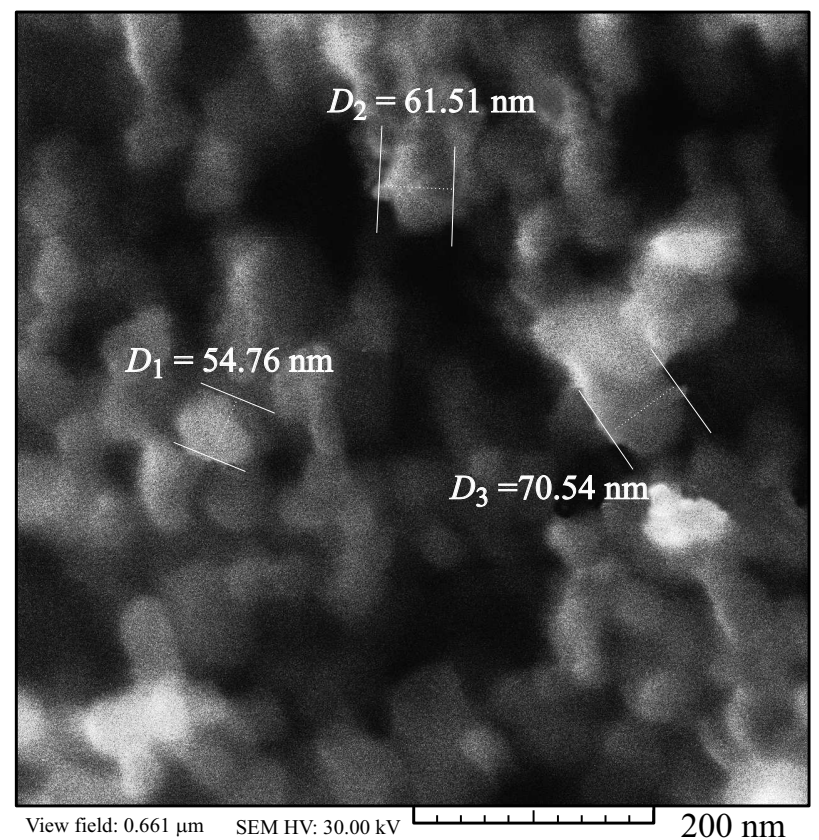

Рис. 1. Микроизображения образцов. $a$ - типичная CTM-3D-топограмма муль-

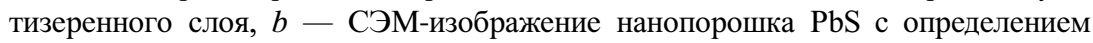
характерного размера зерен. 
роль формы и размеров частиц в мультизеренном слое проводился на сканирующем туннельном микроскопе Nanoeducator-2, NT-MDT (CTMизображение, рис. $1, a)$ и на сканирующем электронном микроскопе (СЭМ-изображение, рис. 1, $b$ ).

Монозеренная структура InSb, InAs, GaAs в виде монослоя субмикронных зерен игольчатой формы с размерами 100-400 nm создавалась при шлифовке алмазным порошком M1 поверхности монокристаллических пластин.

Исследования проводились на приставках зеркального отражения. В ближнем ИК-диапазоне использовался спектральный комплекс на базе монохроматора МДР-41 со сменными дифракционными решетками - 750 lines $/ \mathrm{mm}(0.8-2 \mu \mathrm{m})$ и 600 lines $/ \mathrm{mm}(1-2.5 \mu \mathrm{m})$. В качестве источника излучения использовалась галогеновая лампа, а приемником служил фотоприемник на основе $\mathrm{PbS}(1-2.5 \mu \mathrm{m})$. Для регистрации спектров отражения в области 2.5-25 $\mu \mathrm{m}$ применялся ИК-фурьеспектрометр Nicolet 6700. Эталоном с отражением, близким к 100\%, служило золотое зеркало. Обработка результатов измерений осуществлялась в программном пакете Origin Pro 8 методом Савицкого-Голея с использованием полинома второго порядка.

Измерения методом нарушенного полного внутреннего отражения (НПВО) проводились на ИК-фурье-спектрометре Nicolet 6700 с использованием приставки, позволяющей максимально снизить рассеяние света за счет плотного контакта образца с оптически более плотной средой.

Анализ спектра отражения в области плазменного резонанса выполнялся с помощью основных соотношений для круговой частоты $\omega_{p}$ и длины волны $\lambda_{p}$ в полупроводниках $[3,8]$

$$
\omega_{p}^{2}=n q^{2}(m \varepsilon)^{-1}, \quad \lambda_{p}=2 \pi c / \omega^{\prime}=2 \pi c q^{-1} n^{-1 / 2}(m \varepsilon)^{1 / 2}
$$

где $q$ - заряд электрона, $c-$ скорость света, $\varepsilon-$ абсолютная диэлектрическая проницаемость.

На рис. 2, $а$ приведены типичные спектральные характеристики отражения от мультизеренного слоя в средней ИК-области. Характеристики отражения от тонкошлифованной поверхности пластин имели аналогичный вид (не приведены). При этом степень отражения от подложки была выше, чем от мультизеренного слоя.

Письма в ЖТФ, 2018, том 44, вып. 8 


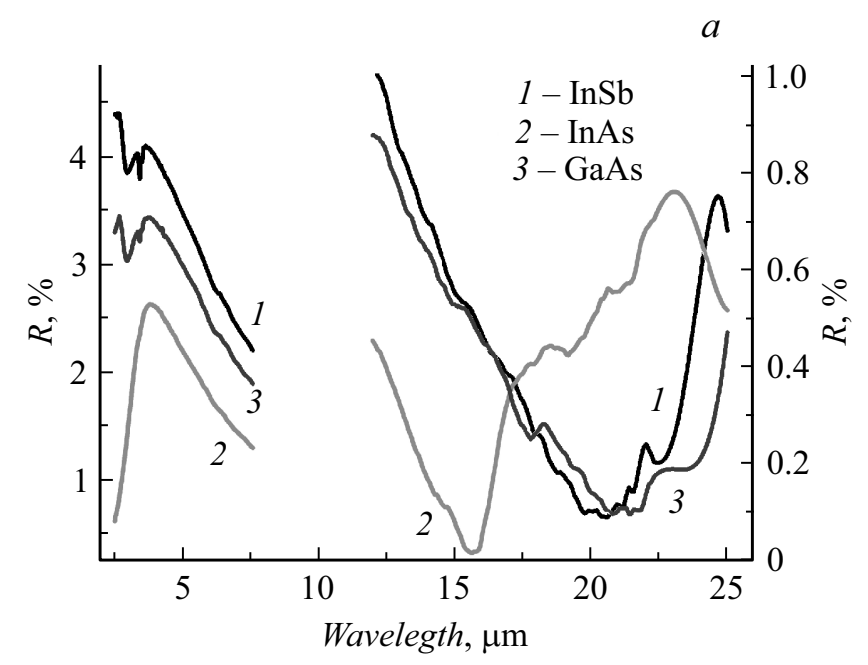

Рис. 2. Спектры отражения: $a$ - мультизеренных слоев в средней ИК-области, $b$ - монозернистой поверхности пластин в ближней ИК-области.

Область плазменного резонанса (рис. 2, $a$ ) по характеру поведения кривых соответствовала известным результатам [4], а значения длины волны $\lambda_{p}$ минимума отражения, обусловленного резонансным поглощением, хорошо коррелировали с параметрами полупроводников $m / m_{0}, n, \varepsilon$. При этом литературные данные и экспериментальные значения для $m / m_{0}$ совпали. Важно отметить, что метод плазменного резонанса дает надежные доказательства того, что в рассматриваемых полупроводниках определяющими эффект являются суперлегкие $\left(m / m_{0} \ll 1\right)$ электроны

Плазменный резонанс в полупроводниках начинает проявляться при условии возникновения взаимодействия электронов в зоне проводимости, т. е. тогда, когда перекрываются их волновые функции. Это означает, что средние расстояния между электронами в этом случае должны быть примерно равны их длине волны де Бройля $\Lambda$, и соответственно концентрация электронов в материале равна $\sim \Lambda^{-3}$. Это значение концентрации, характерное для каждого материала, можно назвать крайним (критическим), выше которого и проявляется плазменный резонанс. 


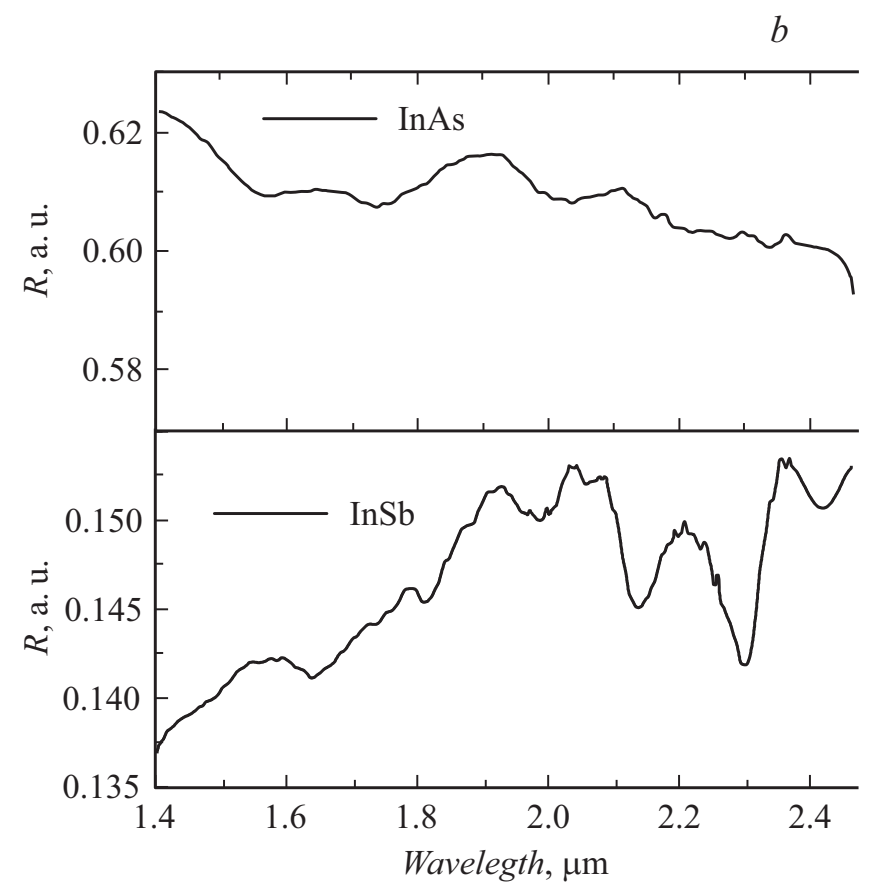

Рис. 2 (продолжение).

В таблице приведены рассчитанные и экспериментальные значения параметров. При расчетах значения энергии электронов в зоне проводимости вычислялись с помощью формулы ферми-статистики по паспортным данным для концентрации $n$ в полупроводниках. Из таблицы следует, что для узкозонных полупроводников характерны относительно низкие значения $n_{c}$ (например, для InSb $n_{c}=2 \cdot 10^{16} \mathrm{~cm}^{-3}$ ). Вычисленные значения длин волн резонансного поглощения при этом могут достигать $100 \mu \mathrm{m}$ в терагерцевом диапазоне.

На всех образцах были исследованы спектральные области собственного поглощения, которое проявлялось в виде провалов на кривых отражения (например, для InAs на рис. 2,a) либо горбов на кривых поглощения (рисунки не приведены). Значения „красной“ границы $\lambda_{r}$ области собственного поглощения представлены в таблице.

Письма в ЖТФ, 2018, том 44, вып. 8 


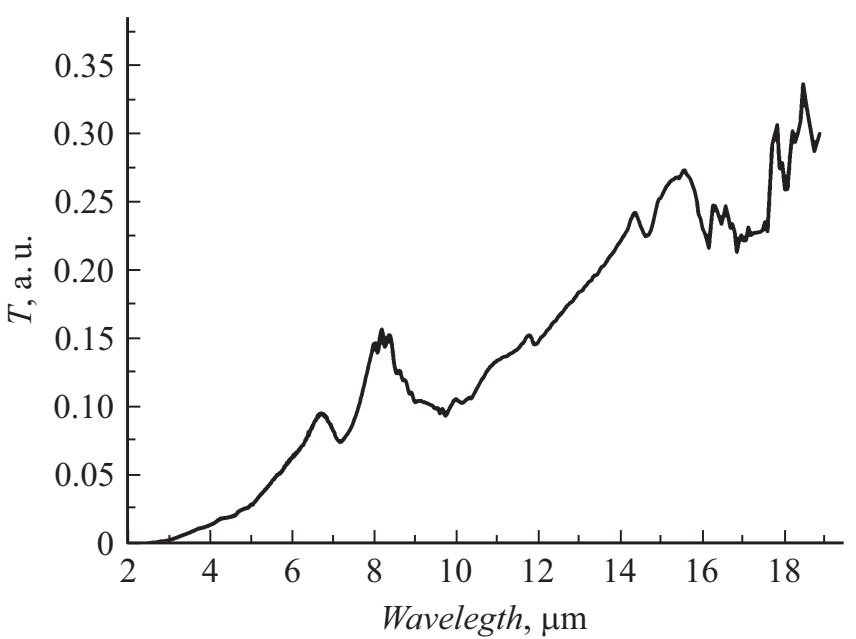

Рис. 3. Спектр пропускания (НПВО) мультизеренного слоя $\mathrm{PbS}$.

На рис. $2, b$ приведены спектры отражения от поверхности подложек InSb и InAs до красной границы собственного поглощения в интервале длин волн $1.4-2.5 \mu \mathrm{m}$. В самом узкозонном полупроводнике $\mathrm{InSb}$ наблюдается поглощение в области $2.1-2.3 \mu \mathrm{m}$. Наличие этой спектральной области поглощения, насколько нам известно, не отмечалось ранее в литературе. Предположительно оно может быть связано с электронными переходами в состояниях кулоновского взаимодействия суперлегких электронов, которое проявляется в виде дискретных уровней с минимальной энергией электронов в полупроводнике со структурой кубической решетки: $E_{l} \sim 12 q(\varepsilon \Lambda)^{-1}$ [1]. Вычисление значений энергии поглощаемых электронами фотонов приводит для $\mathrm{InSb}$ к величине $E_{l}=0.55 \mathrm{eV}$, т.е. длине волны $2.25 \mu \mathrm{m}$, хорошо совпадающей с экспериментальным значением (рис. 2, $b$ ).

На мультизеренном слое $\mathrm{PbS}$ не удалось надежно наблюдать сигнал отражения, и был использован более чувствительный метод НПВО. На рис. 3 представлен спектр пропускания для мультизеренного слоя $\mathrm{PbS}$, где наблюдается несколько минимумов, которым соответствуют максимумы поглощения $17,10,7 \mu \mathrm{m}$. Спектральная зависимость 
на рис. 3 не соответствует обычно получаемым картинам: плазменнорезонансным, подобным приведенным на рис. $2, a$, или интерференционным [9].

С учетом того, что для $\mathrm{PbS} m / m_{0} \ll 1$ и $\Lambda$ может иметь относительно большие значения, его наночастицы размером 50-70 nm (рис. $1, b$ ) можно рассматривать как квантовые точки. Тогда можно считать, что значения энергии электронных переходов должны подчиняться правилам квантования для квантовых точек с размером $a$, и энергетический спектр подчиняется формуле [10]

$$
2^{-1} h^{2} m^{-1} a^{-2}\left(i^{2}+k^{2}+l^{2}\right),
$$

где $i, k, l=1,2,3, \ldots$ - числа, соответствующие номерам уровней (подзон) переходов. Вычисления по этой формуле для значений $m=0.055 m_{0}$ и $a=50 \mathrm{~nm}$ дают ряд величин максимумов поглощения для первых четырех разрешенных уровней (подзон): $34,17,10,7 \mu \mathrm{m}$, что хорошо согласуется с минимумами пропускания на рис. 3 (минимум $34 \mu \mathrm{m}$ аппаратно не разрешен).

Таким образом, в узкозонных полупроводниках с суперлегкими электронами в зоне проводимости при их концентрации, превышающей некое крайнее значение $n_{c}$, связанное с величиной длины волны де Бройля $\Lambda$ для электрона соотношением $n_{c} \sim \Lambda^{-3}$, проявляется плазменно-резонансное отражение, специфика которого состоит в том, что оно может быть длинноволновым, вплоть до $100 \mu \mathrm{m}$. В длинноволновой области $(\lambda>15 \mu \mathrm{m})$ степень отражения от мультизеренного слоя существенно меньше, чем от мелкозернистой (шлифованной) поверхности пластин. Наблюдаемый дополнительный максимум поглощения $2.1-2.3 \mu \mathrm{m}$ для самого узкозонного полупроводника InSb можно объяснить в модели оптического возбуждения кулоновски взаимодействующих электронов. В слое наночастиц $\mathrm{PbS}$ наблюдаются минимумы пропускания (максимумы поглощения), которые можно объяснить электронными переходами по правилам квантования энергии для квантовых точек.

Исследование выполнено при финансовой поддержке РФФИ в рамках научного проекта № 16-07-00226.

Письма в ЖТФ, 2018, том 44, вып. 8 


\section{Список литературы}

[1] Жуков Н.Д., Глуховской Е.Г., Мосиям Д.С. // ФТП. 2016. Т. 50. В. 7. C. 911-917.

[2] Глуховской Е.Г., Жуков Н.Д. // Письма в ЖТФ. 2015. Т. 41. В. 14. С. 47-53.

[3] Роках А.Г., Биленко Д.И., Шишкин М.И., Скапцов А.А., Вениг С.Б., Матасов М.Д. // ФТП. 2014. Т. 48. В. 12. С. 1602-1606.

[4] Маделунг $O$. Физика полупроводниковых соединений элементов III и V групп. М.: Мир, 1967. 477 с.

[5] Зимин С.П., Горлачев Е.С. Наноструктурированные халькогениды свинца. Ярославль: ЯрГУ, 2011. 232 с.

[6] Лукашин А.В., Елисеев А.А. Синтез полупроводниковых наночастиц сульфида свинца и сульфида кадмия. М.: МГУ, 2011. 38 с.

[7] Dixon J.R., Riedl H.R. // Phys. Rev. 1965. V. 140. N 4A. P. A1283-A1291.

[8] Оура К., Лифиии, В.Г., Саранин А.А., Зотов А.В., Катаяма М. Введение в физику поверхности. М.: Наука, 2006. С. 116.

[9] Панов М.Ф., Томаев В.В. // Физика и химия стекла. 2012. Т. 38. № 4. C. 543-552.

[10] Драгунов В.П., Неизвестный И.Г., Гридчин В.А. Основы наноэлектроники. М.: Физматкнига, 2006. 496 с. 